\title{
Dossiê:
}

Gêneros e feminismo(s): novas perspectivas teóricas e caminhos sociais 



\section{Corpo feminino e violência de gênero: fenômeno persistente e atualizado em escala mundial}

Tânia Mara Campos de Almeida*

E mbora a categoria gênero tenha sofrido desgastes ao longo de sua trajetória acadêmica, causando hoje críticas e recusa por parte de algumas estudiosas em utilizá-la, ainda se mostra proveitosa para marcar uma perspectiva dessencializadora e biologicizante das identidades baseadas nas diferenças de âmbito sexual, tanto nos meios universitários como nos meios legislativos, jurídicos e governamentais. Do mesmo modo, é pelo seu emprego que se entende o fato de a violência contra mulheres e contra pessoas que ocupam posições ditas feminizadas nas sociedades de modo geral (crianças, idosos, dentre outros/as de acordo com circunstâncias momentâneas) emergir a partir da questão da alteridade, enquanto fundamento distinto de outros tipos de violência.

Ao se optar pela modalidade "violência de gênero", vê-se que as ações violentas são produzidas em contextos e espaços sociais relacionais, quer sejam interpessoais quer sejam da ordem impessoal ou de grandes guerras. Isto é, essa violência não se refere a atitudes de fazer sofrer ou aniquilar o outro que seja alguém considerado igual ou que é visto nas mesmas condições de existência e valor que o/s seu/s perpetrador/ es. A centralidade das ações violentas (físicas, sexuais, psicológicas, patrimoniais ou morais) incide sobre a alteridade do feminino na esfera doméstico familiar, na esfera pública e na esfera dos conflitos internacionais.

O movimento feminista e o movimento de mulheres, em suas diferentes gerações, matizes de pensamento e tendências políticas, vêm declarando a expressiva concentração deste tipo de violência sobre os corpos femininos situados em cenas rotineiras de assimetria frente aos corpos e aos polos superiores do poder masculino durante um longo período da história da humanidade até nossos dias. A atuação e as reivindicações da militância feminista criaram as condições históricas, políticas e culturais necessárias ao reconhecimento da legitimidade e da gravidade da questão, aliando-se a esforços acadêmicos para dar visibilidade sociológica a essa violência entre os muros universitários, entre os governos e no seio da sociedade civil.

Haja vista que a elaboração do fenômeno da violência contra as mulheres como problema de Estado tem sido um crescendo na América Latina, provocada pelas denún-

\footnotetext{
* Departamento de Sociologia; Núcleo de Estudos e Pesquisas sobre Mulher. Universidade de Brasília. <taniamaraca@unb. br>.
} 
cias de organizações feministas e defensoras dos direitos humanos de suas vítimas e familiares, bem como pelos inúmeros resultados de pesquisas científicas. O empenho de destacadas acadêmicas feministas, que diante da insensibilidade dos governos, do desdém da imprensa, da impunidade das autoridades e dos preconceitos sexistas das sociedades latinas em seu conjunto, tem produzido abundante literatura descritiva e analítica sobre o fenômeno.

Contudo, apesar de avanços na seara dos direitos, da disseminação de programas que protegem esses direitos, da mudança de mentalidades e do reconhecimento jurídico nacional e internacional da cidadania das mulheres e demais grupos feminizados em igualdade à dos homens, a realidade evidencia uma expressiva quantidade de casos de violência, que têm se apresentado cada vez mais truculentos e cruéis. Afinal, resistências conservadoras se revelam em centenas de espaços sociais e sob formas variadas contra a efetivação de novas relações entre homens e mulheres. Novamente, confirma-se que a violência de gênero constitui-se em um fenômeno social persistente, multiforme e articulado por facetas psicológica, moral, física e econômica, tanto em nível micro como macrossociológico.

O presente dossiê temático, intitulado "Gênero e feminismo(s): novas perspectivas teóricas e caminhos sociais", foi organizado por Lourdes Maria Bandeira e por mim, ambas professoras do Departamento de Sociologia, atuantes na consolidada linha de pesquisa "Feminismos, relações de gênero e raça" da nossa pós-graduação e integrantes do Núcleo de Estudos e Pesquisas sobre Mulher (NEPeM), da Universidade de Brasília (UnB). Há tempo que desejávamos preparar uma contribuição significativa para o referido debate temático, especialmente por já completar praticamente duas décadas do Volume 12 / Número 2 (julho-dezembro de 1997), o primeiro e até então único da Sociedade e Estado dedicado a "feminismos e gênero", o qual frequentemente é citado em investigações, cursos e demais atividades acadêmicas.

A partir deste conjunto de seis artigos de renomadas e experientes estudiosas do assunto, alcançamos tal intento. Afinal, ao considerar a violência contra as mulheres em escala mundial, no continente latino-americano e na especificidade brasileira, as autoras fornecem respostas por diferentes ângulos de análise e reflexão, que ajudam a identificar tipificações e lógicas particulares da violência de gênero desferida aos corpos femininos, conferindo novos contornos ao assunto, tanto em caráter acadêmico, ativista, jurídico como na ordem das políticas públicas. Colegas brasileiras e mexicanas encontram-se ora juntas, oferecendo-nos um perfil relevante das investigações que vêm sendo realizadas nesses países e, de modo mais amplo, no continente latino-americano, conforme as breves sínteses apresentadas a seguir.

O primeiro dos artigos, "Las nuevas formas de la guerra y el cuerpo de las mujeres", de autoria de Rita Laura Segato (Universidade de Brasília - UnB), apresenta sofistica- 
dos modelos teóricos que têm atraído interesse não apenas nas fronteiras brasileiras. Em linhas gerais, aborda as atuais formas de guerra, marcadas pela informalidade e por situarem-se em espaço controlado por corporações armadas com participação de efetivos estatais e paraestatais.

No continente latino-americano, encontram-se sob diversas faces, de modo não convencional por não se apresentarem como guerras deflagradas formalmente entre Estados e por delas participarem efetivos e corporações armadas estatais e não estatais. Trata-se de um universo mafioso da cena bélica difusa e em franca expansão, vinculado à informalidade da economia e ao aumento do capital não declarado em crimes organizados. Eventos de violência que se apresentam fragmentados e de baixa inteligibilidade parecem estar à margem da vida social e serem apenas da ordem da segurança pública e sua gestão, mas participam de uma gigantesca estrutura que interfere diretamente na política e nos governos, constituindo-se em um "Segundo Estado" (Segato, 2006).

Nesse espaço, a violência contra as mulheres tem deixado de caracterizar-se como simples efeito secundário das guerras para transformar-se em exibição de espetáculo de poder. Emerge agora uma "pedagogia da crueldade" contra aquelas que não desempenham o papel de antagonistas armadas nos embates, sendo vítimas sacrificiais por ser nelas que se inscreve a mensagem de soberania destinada ao antagonista. As guerras da antiga lugoslávia e de Ruanda são paradigmáticas dessas transformações, onde a agressão sexual passou a ocupar posição central como arma de guerra produtora de crueldade e letalidade, que se dão simultaneamente de modo material e moral no corpo feminino como um território expropriado e destruído.

Desde as guerras tribais, o corpo das mulheres e os corpos feminizados sempre foram imbuídos de significado territorial, sendo considerados corpos cuja existência ocorre sob custódia dos homens (pai, marido, irmão e filhos) e acompanharam o destino das conquistas e anexações dos grupos inimigos. Mas, hoje, vê-se a destruição delas com excesso de exploração, tortura e morte, dirigindo insensibilidade e truculência a toda à comunidade nelas representadas. Não há mais respeito por nenhum regramento à proteção desses grupos femininos e o que poderia ser um "costume" militar se torna um comportamento planejado, tornando o comportamento nessas guerras altamente sexualizado e o corpo um terreno-território da própria ação bélica.

Essas guerras não se destinam mais a alcançar um fim. Possuem um projeto lucrativo de longo prazo em sintonia com o mercado global, em meio ao cenário da modernidade tardia, à decadência da "democracia real", à porosidade dos Estados nacionais e à transformação do paradigma territorial. Sem vitórias ou derrotas definitivas, em alguns lugares do planeta, seriam praticamente uma forma de existência. Tal contexto 
de mudança da guerra é também o de mudança de outras dimensões inter-relacionadas da vida: a territorial, a política, o Estado, a economia e o patriarcado.

A autora desenvolve mais profunda e sistematicamente nesse artigo ideias que já tinham sido apresentadas em trabalhos anteriores e sob outros ângulos de análise, por exemplo: a função propriamente expressiva, não apenas instrumental, de todos os tipos de violência de gênero (Segato, 2003). Essas guerras expressam o espírito de corporação dos seus perpetradores e transformam o corpo das mulheres em suporte no qual a estrutura bélica se manifesta e se reproduz, uma vez que nele se escreve a derrota moral do inimigo, especialmente quando não há um documento formal de rendição em situações de informalidade.

Ao finalizar, torna-se claro que não se trata de crimes de motivação sexual ou de "ódio". Portanto, não podem ser privatizados e banalizados em explicações monocausais. Há uma grande variedade de crimes de gênero, que devem ser tipificados. Estes são crimes de guerra e, como tais, devem ser analisados a partir de outros modelos e novas categorias jurídicas, em especial no campo dos direitos humanos e da justiça humanitária. Por enquanto, estes crimes, que se mantêm impunes, têm sido a expressão do poder que não tem motivações de fórum íntimo ou ordem doméstica. A estes tipos de feminicídios, a autora sugere denominar de "femi-geno-cídios" (Segato, 2011 e 2012).

O segundo artigo do dossiê, "Sociología y política del feminicidio; algunas claves interpretativas a partir de caso mexicano", escrito por Teresa Incháustegui Romero (Universidad Autonónoma de la Ciudad de México - UACM), foca a relação entre crise da ordem patriarcal e o questionamento das formas de dominação masculina diante do surgimento social das mulheres e o incremento da violência feminicida. A violência contra as mulheres atua como dispositivo de poder masculino para restabelecer ou manter, simultaneamente no nível individual e coletivo, as posições de domínio varonil e atuar como instrumento de controle para conter as transgressões das mulheres aos tradicionais regimes de gênero, que estariam experimentando transições produzidas por sua inserção no espaço cultural-simbólico, na vida pública e no mercado de trabalho.

Tais mudanças identitárias das mulheres, sobretudo as mais jovens em seus papéis e expectativas pessoais e sociais, estilos de vida, dentre outros, têm sido consideradas como uma profunda ruptura histórica de grandes consequências econômicas, políticas e culturais, já que estariam levando abalos estruturais entre os sexos, além de provocar desafios econômicos e da ordem civilizatória em grande escala. A saída massiva das mulheres de seu nicho estrutural para as atividades remuneradas, o exercício de profissões e cargos diversos, que se tem produzido na América Latina, não apenas 
estabelece uma alteração política, econômica e simbólico-cultural de significativa envergadura para as políticas públicas, senão também diz respeito ao funcionamento do mercado e da organização espacial em termos de reconciliar as racionalidades e o funcionamento de esferas sociais até agora somente vinculadas pela mediação do consumo: o trabalho e a família. Somado a isso, emerge um contexto de hibridação cultural também em matéria de gênero, que mistura formas e tendências diversas no campo da sexualidade e das identidades de gênero.

Sua hipótese central para uma sociologia da violência de gênero e do feminicídio seria que a brecha gerada entre um modelo de gênero normativo, centrado na subordinação das mulheres e na emergência social da figura feminina, como figura de poder e autonomia, está presente nas diversas vertentes das relações cotidianas que sustentam homens e mulheres entre si, seja no plano das relações interpessoais como no das relações simbólicas e de poder que atuam no espaço público. Assim, todo tipo de violência contra a mulher é expressão de uma resposta emocional reativa, instrumentalizada dos homens para manter ou recuperar as fronteiras de gênero socialmente estabelecidas, mantendo ou defendendo as prerrogativas e os privilégios masculinos diante do rebaixamento que representam as margens de empoderamento físico, econômico e político, especialmente obtidos pelas mulheres nas três últimas décadas.

Para mostrar tal situação, conceitos são aclarados em seus sentidos teóricos e políticos, como são apresentados em uma perspectiva histórica. A autora dedica parte do seu artigo à construção teórica e ao sentido político do conceito feminicídio. Essa passagem começa com a construção do termo femicídio e sua conceptualização, que tem uma matriz feminista e, portanto, política. Em específico, foi lançado em Bruxelas no ano de 1976, por Diana Rusell, em um fórum de feministas reunindo representantes de 40 países sob o nome de Tribunal Internacional de Crimes contra as Mulheres. A partir das modalidades, motivações e características destes crimes, apresenta um conjunto de definições que são resultado da evidência construída a partir da denúncia, do registro e acompanhamento dos casos que surgem diariamente em várias cidades da América Latina. Algumas dessas definições elencadas pela autora são: o feminicídio íntimo, o feminicídio sexual, o feminicídio corporativo ou de Segundo Estado; o feminicídio infantil.

A base empírica para pensar tais conceitos foram os dados do registro de estatísticas de mortalidade por meio das certidões de óbito (certificados de defunción) de 1985-2010 no México, permitindo observar os tipos de feminicídio perpetrados no país no transcurso de gerações que viveram o surgimento, o esplendor e a crise do Estado desenvolvimentista. A sistematização do registro forense de mortes violentas por assassinato entre homens e mulheres permitiu apreender os níveis de violência 
que vivem as/os mexicanas/os tanto no mundo público como privado, bem como perceber traços e tendências muito diferentes entre a dinâmica da mortalidade entre os gêneros. O que revelou ser violência letal sobre as mulheres evidencia uma violência baseada no gênero, enquadrando-se nos termos da definição de violência feminicida (Incháustegui Romero y Olivares, 2009).

Essa sistematização também indica deslocamentos geográficos e características regionais do fenômeno, o que apontaria para a existência de contextos socioculturais normativos, favorecedores da violência contra as mulheres em suas modalidades mais agressivas, articuladas com fatores propulsores como a violência social, a violência criminal, a proliferação de armas e a impunidade reinante em praticamente todo o país. Em particular e de modo emblemático, os feminicídios repertoriados em Ciudad Juárez são o maior escândalo e provocam a maior indignação na população, uma vez que as autoridades responsáveis por perseguir e punir autores de tais delitos não apenas agiram com omissão, mas com pouca atenção e desprezo.

Por fim, as tendências e novas expressões do feminicídio no México apontam para cinco comentários sintéticos:

1. a existência de certa constância desse tipo de violência, uma vez que os casos são pouco reduzidos nos anos de baixa taxa geral de homicídios e aumentam rapidamente quando a violência social está incrementada;

2. a identificação de um núcleo duro histórico de estados mexicanos com forte incidência de feminicídio e outro que está sendo qualificado de núcleo emergente;

3. a confirmação de que a condição de ser mulher está na origem da violência, logo os feminicídios são crimes de ódio contra as mulheres e exibem o poder e domínio dos homens sobre elas, estando presente em todas as gerações e possuindo uma dinâmica multimodal;

4. o surgimento de uma nova epidemiologia desses crimes, já que muIheres cada vez mais jovens e solteiras têm constituído um grupo expressivo de vítimas, bem como o crescimento dos feminicídios na via pública com uso frequente de arma de fogo; e

5. a violência feminicida não teria tomado feição epidêmica no México sem o silenciamento dos órgãos públicos em diversos governos.

O terceiro capítulo, "Desde la complejidad y la ética de la investigación: paradojas de los discursos biomédicos sobre la violencia de género en México", de María Guadalupe Huacuz Elías (Universidad Autónoma Metropolitana Xochimilco - UAM-Xo- 
chimilco), explora, a partir do método da complexidade, da ética em pesquisa e do feminismo crítico, os discursos universalistas, dicotômicos, totalizadores e a-históricos da biomedicina, sobre a violência de gênero presentes nos sistemas de saúde no México. Embora os/as analistas teóricos/as sobre o tema na área médica tenham recorrido a diversas disciplinas do conhecimento (psicologia, antropologia, direito, filosofia, literatura, dentre outras), a maioria dos textos intenciona identificar e isolar as "causas" da violência contra as mulheres e seus "efeitos" na vida dessas muIheres e uma base de conhecimento linear.

Seu objetivo é refletir sobre os paradoxos neles existentes que acabam por se basear na apropriação do corpo das mulheres via medicalização e por propor a implementação de estratégias simples frente à problemática. Ou seja, o discurso biomédico encarnado nas instituições de saúde reproduz os vícios dos saberes médicos hegemônicos, tais como o controle do corpo das mulheres, a simples medicalização das mulheres em situação da violência, a expropriação da autonomia das mulheres mediante a fixação delas no lugar de "eternas vítimas" e a transformação do fenômeno em pandemia social.

A autora enfatiza as consequências na saúde vivida pelas mulheres afetadas pela violência, incluindo as pessoas responsáveis pela intervenção. Afinal, o modelo biomédico está construído de maneira tão consistente que dificilmente se pode romper com as estruturas falocêntricas (Huacuz Elías, 2011) que o sustentam, assim como esse modelo acaba por reforçar o imaginário coletivo de que esse tipo de violência é exclusivo de classes sociais empobrecidas e de um grupo específico de mulheres exposto a um homem agressor visto individualmente.

Não é possível pensar esse fenômeno social sem considerar um pensamento complexo, em que as estruturas patriarcais e capitalistas fazem dos corpos das mulheres objetos de múltiplas violências. Estas se reproduzem constantemente e como respostas às pressões de um sistema econômico, político e cultural globalizado. Somente desse modo será possível deixar de lançar um olhar reducionista sobre tal violência contra as mulheres.

O quarto artigo, "Pensar el cuerpo de las mujeres: cuerpo, belleza y feminidad. Una necesaria mirada feminista”, escrito por Elsa Muñiz (Universidad Autónoma Metropolitana Xochimilco - UAM-Xochimilco) discute a importância de se realizar uma análise feminista, por intermédio da apresentação e discussão de filmes recentes, a respeito dos corpos das mulheres nas sociedades contemporâneas da América Latina. A partir de um conjunto de discursos e práticas, que levam as mulheres a buscarem os mais altos padrões de beleza e perfeição femininas sob normas rigorosas exigidas pela cultura de gênero hegemônica e contemporânea, imagens e representações da 
beleza feminina são difundidas para o consumo e a constituição de profundos processos de subjetivação.

Para tanto, dedica reflexões às cirurgias plásticas, seus altos custos e efeitos colaterais às mulheres que a elas submetem-se. Em especial, atenção é dada às "etnocirurgias", termo apresentado pela própria autora em trabalho anterior (Muñiz, 2011). Esta intervém diretamente na autopercepção dos sujeitos, já que as modificações corporais de "correção" dos traços corporais e faciais possuem implicações na definição identitária e em seus processos de subjetivação. Se os grupos de classes médias têm recorrido a estes serviços estéticos com grande soma de recursos financeiros, os grupos das camadas de baixa renda têm se submetido a tratamentos clandestinos, com riscos graves de sequelas irreversíveis e de morte. Isso, portanto, tem se tornado um problema de saúde pública.

Esse conjunto de modelos de beleza desconhece e exclui qualquer tipo de diferença ao fenótipo branco e europeizado. Tais padrões promovem a discriminação racial, as pessoas portadoras de deficiências e todas aquelas mulheres que não cumprem com as características estabelecidas como padrão almejado na cor da pele, estatura, nas formas e nos olhos, dentre outras. Esta imposição tornou-se um grave problema de discriminação em uma sociedade heterogênea e miscigenada como a mexicana e, também, em toda a América Latina.

Por isso, a autora considera fundamental que o feminismo discuta essa problemática contemporânea, não somente porque o feminismo e a análise de gênero romperam com o olhar essencializado da diferença sexual como preestabelecida biologicamente e corporeamente, também porque criticaram a noção de feminilidade onde a beleza se constitui um imperativo automático para a condição de ser mulher. Uma parte do artigo é dedicada à perspectiva feminista e ao mito da feminilidade, estabelecendo uma discussão com o construtivismo a partir do qual se observa o corpo como mera superfície de inscrição, anterior aos discursos socioculturais. Ao assumir a crítica à essa ideia de corpo como suporte biológico da cultura, pode-se assumi-lo como resultado dos efeitos do poder produtivo. Logo, é importante considerar a historicidade das práticas de beleza para vincular a individualidade a um contexto mais amplo de poder e hierarquias de gênero, mas analisando o complexo e contraditório trabalho dos discursos sobre o corpo, o controle e a feminilidade.

Em outra parte do artigo, é exposta a maneira em que as práticas corporais da beleza como cirurgia plástica assumem um caráter performativo e materializador dos sujeitos de gênero. As práticas de beleza não são simplesmente um artefato de consumo capitalista, de feminilização da cultura ou das contradições da Modernidade. São centrais à reprodução das relações de dominação e subordinação, ao perpetuar as limitações e os efeitos disciplinares da feminilidade. 
Essa discussão não pode ser compreendida sem tomar em conta o gênero, o poder e a corporalidade na cultura ocidental. Por isso, a análise das práticas culturais e do discurso sobre a beleza produz importantes significados para a compreensão não apenas dos processos que levam a cabo a materialização dos corpos, mas também permite conhecer as razões pelas quais as mulheres persistem em "melhorar" ou alterar seus corpos, apesar dos perigos e dos mal-estares da maioria das intervenções e tratamentos de beleza.

O quinto artigo, "Corpo, geração e identidade: a Marcha das Vadias no Brasil", assinado em coautoria por Carla Gomes e Bila Sorj (ambas da UFRJ), mostra que, diferentemente das afirmações sobre o desaparecimento do movimento feminista, nota-se sua presença constante e dinâmica na sociedade brasileira, marcada por uma gama ampla de expressões coletivas, identidades políticas e variados graus de institucionalização e de relações entre os grupos internos.

O objetivo do artigo é explorar, a partir da análise do movimento social denominado por Marcha das Vadias, os contrastes e as continuidades entre diferentes gerações de feministas no país, especialmente em relação ao modo como a questão da diversidade e inclusão dos grupos de mulheres nele vem sendo tratada. Cabe frisar que esse movimento é tema polêmico entre feministas, mas alcançou repercussão desde seu surgimento. Essas versões brasileiras do movimento fazem alusão ao protesto feminista que começou em Toronto (Canadá) no ano de 2011. A adoção do termo "vadia" é uma subversão ao uso acusatório do termo, reivindicando sua ressignificação positiva como força de luta, como "empoderamento". Os dados analisados nesse artigo foram apreendidos e elaborados por meio de pesquisa documental e de observação participante junto à organização da Marcha das Vadias do Rio de Janeiro e acontecimentos da marcha em Brasília, no ano de 2013.

A opção das autoras por tratar as ativistas feministas em termos de gerações, em vez de considerá-las nos habituais quadros temporais sucessivos, como as conhecidas "ondas" da história do feminismo internacional mainstream e do feminismo nacional, por viabilizar a agregação de diferentes ativistas ao mesmo tempo, mantendo entre elas relações conflituosas e de solidariedade. Conforme afirmam:

De fato, o feminismo sempre foi um movimento descentralizado, constituído de diferentes grupos de mulheres, com variadas experiências de vida e modos diversos de conceber o tema das relações de gênero, de formular ideologias e estratégias políticas.

Chama a atenção a presença, ora em disputa ora em articulação, de diversos coletivos de jovens mulheres feministas, homens e pessoas LGBTIs no movimento, deixando de ser um espaço exclusivo das mulheres, vistas pelo viés da identidade sexual e biológi- 
ca. Isso é apontado como a principal descontinuidade com expressões do feminismo cronologicamente anterior e, de modo conclusivo, o artigo aponta para este ser um desafio a conviç̧ões feministas consideradas como clássicas, como serem apenas as mulheres seus sujeitos políticos.

O corpo aí também se destaca centralmente, conforme nas manifestações feministas do passado. Contudo, na atualidade, atua em importante e duplo papel. Por um lado, o corpo é objeto de reivindicação (autonomia das mulheres sobre seus corpos), extrapolando o tema da descriminalização do aborto, do planejamento familiar e da saúde da mulher, como em movimentos anteriores. Torna-se assim uma bandeira de modos de experimentação do corpo vivenciada na liberdade de cada sujeito por meio da nudez, da sensualidade, das diferentes aparências etc., expostas no movimento nas ruas. Por outro lado, o corpo é apresentado no lugar de principal instrumento de protesto, sendo um relevante suporte de comunicação do movimento em si.

Ressalta-se ainda o quanto a identidade de raça/cor pode ser articulada de diversos modos em sua relação com o feminismo. Uma tensão marcada emerge de movimentos de feministas e de mulheres negras que veem a marcha como o acirramento de um distanciamento histórico entre elas e as mulheres brancas de classe média e universitárias, as quais estão à frente de várias das marchas no país. Simultaneamente, outras feministas e mulheres negras integram-se ao movimento, sendo relativizadoras à leitura de divisões do feminismo em linhas raciais e reafirmam a possibilidade de serem por ele representadas.

O sexto artigo do dossiê, "Violência de gênero: a construção de um campo teórico e de investigação," de Lourdes Maria Bandeira (Universidade de Brasília - UnB), trata da violência contra a mulher, ao mesmo tempo em que enfoca a condição de gênero como categoria de análise. Tal condição de gênero é compreendida como fundamental para a compreensão da dinâmica do fenômeno violento e para seu efetivo enfrentamento, em especial nas esferas da segurança pública, da saúde, do judiciário e da própria sociedade civil.

Inicialmente, a autora localiza a precedência histórica da construção desse campo de estudo e de pesquisa no âmbito das ciências sociais, particularmente da sociologia, sob um olhar feminista no país. Na verdade, mostra como esse campo teórico-metodológico e de ação política foi se constituindo a partir das reivindicações do movimento feminista internacional e brasileiro, correlacionadas com espaços de militância acadêmica, por meio, em especial, dos núcleos de pesquisa em universidades federais. 
O pensamento acadêmico, na perspectiva feminista, ao tentar explicar a violência de gênero, defrontou-se com uma diversidade de explicações conceituais e metodológicas, que, grosso modo, são sintetizadas nessas cinco linhas de indagações pela autora:

a. a hegemonia do poder masculino, que permeia as relações entre homens e mulheres;

b. a condição de subalternidade feminina, baseada na hierarquia de gênero;

c. a reprodução das imagens de homem e mulher e dos papéis a ambos atribuídos por meio da construção social da violência;

d. a existência disseminada e, ao mesmo tempo, invisibilizada das violências nas relações familiares e sociais; e, por fim,

e. a presença das dissimetrias organizadoras das normas e regras sociais em relação aos comportamentos de homens e mulheres.

Além disso, os estudos feministas sobre a violência de gênero consideram, em especial, a violência contra a mulher como um dos pilares do patriarcado e, de modo correlato, a posição de dominação simbólica masculina. Contudo, reconhecem que há outros elementos que compõem a dinâmica da violência. Dessa forma, o patriarcado e a dominação masculina, se tomados isoladamente, seriam causas insuficientes para se explicar a violência contra a mulher. Apesar das fragilidades que ambos os conceitos apresentam na sociedade contemporânea, bem como das críticas que thes são atribuídas, ainda trazem consigo significados e desdobramentos importantes para que se possa compreender a manutenção dos ordenamentos familiares.

Data dos anos 1980 o estabelecimento efetivo dessa nova área de estudos e ação, levando à criação de serviços públicos especializados, leis particulares e a incorporação transversal das reflexões de gênero na seara Estatal (Bandeira e Almeida, 2013). Assim, o artigo segue abordando a categoria de violência contra a mulher como questão central no cotidiano, uma vez que o volume de denúncias das mais variadas formas de violência contra as mulheres tem persistência como relevante fenômeno social. Na sequência, destaca-se o surgimento dos locais institucionais de acolhimento das denúncias desse fenômeno social, como as Delegacias Especializadas de Atendimento à Mulher (Deam's), assim como da área de saúde que, a partir dos anos 1990, intensificou-se, e do Ligue 180 nos anos 2000. Por fim, destaca-se o marco jurídico de avanço nos direitos presentes na Lei Maria da Penha (n. 11.340, de 7 de agosto de 2006) e na sua efetiva aplicação. 
Enfim, este conjunto de seis artigos, constituintes do dossiê "Gênero e feminismo(s): novas perspectivas teóricas e caminhos sociais", tem a oportunidade de oferecer interessantes modelos teóricos e reflexões diversificadas, situados em especial no contexto latino americano das ciências sociais, sobre corpo feminino e violência de gênero ao público interessado nessa temática.

\section{Referências}

BANDEIRA, Lourdes Maria; AlMEIdA, Tânia Mara C. A transversalidade de gênero nas políticas públicas. Revista do Centro de Estudos Avançados Multidisciplinares (Ceam), v. 2, Universidade de Brasília, 2013, p. 35-46.

Huacuz Elías, María Guadalupe. La bifurcación del caos. Reflexiones interdiciplinarias sobre violencia falocéntrica. México: Universidad Autónoma Metropolitana-Xochimico-Itaca, 2011.

Incháustegui Romero, Teresa; Olivares, Edith. Del dicho al hecho. Elementos para una historia de la política para una vida libre de violencia en México. México: Conavim, 2009.

MUÑIz, Elsa. La cirugía cosmética: ¿Un desafó a la naturaleza? México: CONACyT-UAM, 2011.

Segato, Rita Laura. Las estructuras elementales de la violencia. Buenos Aires: Prometeo; Universidad Nacional de Quilmes, 2003.

- La escritura en el cuerpo de las mujeres asesinadas en Ciudad Juárez. Territorio, soberanía y crímenes de Segundo Estado. México: Ediciones de la Universidad del Claustro de Sor Juana, 2006.

- Femi-geno-cidio como crimen en el fuero internacional de los derechos humanos: el derecho a nombrar el sufrimiento en el derecho. In: Fregoso; Rosa-Linda; Bejarano, Cynthia (Eds.). Feminicidio en América Latina. Mexico: Centro de Investigaciones de Ciencias Sociales y Humanidades and Universidad Nacional Autónoma de México, 2011.

— . Femigenocidio y feminicidio: una propuesta de tipificación. Revista Herramienta, n. 49, 2012. 